\title{
INMIGRACIÓN Y GLOBALIZACIÓN: UNA APROXIMACIÓN DESDE LOS MEDIOS DE COMUNICACIÓN ESCRITOS ESPAÑOLES
}

\author{
IMMIGRATION AND GLOBALIZATION: AN APPROACH FROM THE \\ PRINTED SPANISH MASS MEDIA
}

\author{
Juan Antonio Roche Cárcel \\ Carmen Marimón Llorca \\ Universidad de Alicante. España/Spain \\ ja.roche@ua.es \\ marimon@ua.es
}

Recibido/Received: 12/11/2011

Modificado/Modified: 18/01/2012

Aceptado/Accepted: 30/01/2012

\section{RESUMEN}

Pretendemos mostrar qué tipo de representación social del inmigrante y/o la inmigración proporciona la prensa española y comprobar hasta qué punto ésta puede construir y alimentar imaginarios que hagan muy difícil la práctica de la interculturalidad. Queremos analizar el grado en el que nuestras ciudades globales se rigen aún por coordenadas locales y territoriales o si, por el contrario, la llegada de inmigrantes está trayendo consigo un nuevo concepto de ciudadano y de identidad cultural. Nos interesa, en definitiva, explorar qué modelo de identidad transmiten y consolidan los medios de comunicación y si éste sirve para fomentar el diálogo entre culturas o si, por el contrario, está contribuyendo a perpetuar la brecha entre el "nosotros" y el "ellos".

\section{PALABRAS CLAVE}

Sociología del lenguaje, análisis del discurso, ideología, medios de comunicación, migraciones, globalización.

\section{SUMARIO}

1. Introducción: el discurso del poder o el poder del discurso. 2. El lenguaje como productor de realidad: el discurso de la prensa y la manipulación de la información. 3. Las migraciones en el contexto de la globalización. 4. Identidad y multiculturalismo. 5. Los condicionantes espacio-temporales de las migraciones globales. 6. La ciudad y los inmigrantes: análisis y resultados. 7. Conclusiones. Bibliografía.

\footnotetext{
ABSTRACT

The aim of this work is to show how immigrants and immigration are represented in the Spanish press and to try to demonstrate the way news can create and feed social false conceptions that make the practice of interculturality very difficult. We want to analyze the degree to which localities and territories still control our global cities and in what manner the arrival of immigrants carries with it a new concept of citizen and identity. Finally, we are interested in exploring the identity model that the mass media communicates and consolidates and if this serves to promote dialogue between cultures or, on the contrary, is perpetuating the gap between "us" and "them."
} 
KEY WORDS

Sociology of language, discourse analysis, ideology, mass media, migrations, globalization.

\section{CONTENTS}

1. Introduction: the speech of power or power of speech. 2. Language as a producer of reality: the speech of the press and the handling of information. 3. Migration in the context of globalization. 4 . Identity and multiculturalism. 5. The space-time determinants of global migration. 6. The city and immigrants: analysis and results. 7. Conclusions. References

\section{INTRODUCCIÓN: EL DISCURSO DEL PODER O EL PODER DEL DISCURSO}

En un trabajo sobre las relaciones entre el discurso y el poder, Enrique Luque Baena (1996:37-56) señalaba que el lenguaje, lejos de ser únicamente la mera expresión de realidades, es también "productor de las mismas; en otras palabras, el sociólogo viene a decirnos que, cuando damos o recibimos información a través del lenguaje, éste no se comporta como un mero medio transmisor, sino que se convierte en el mensaje mismo. Este punto de vista nos acerca a la potencialidad constructora de la lengua, a su naturaleza como instrumento privilegiado para crear y comunicar significados, al papel de los mecanismos lingüísticos en la elaboración de la realidad, en otras palabras, a la forma en que los discursos construyen las representaciones sociales que nos permiten comprender el mundo y vivir en sociedad.

Nos proponemos mostrar qué tipo de representación social del inmigrante y/o la inmigración proporciona la prensa y comprobar cómo esta puede construir y alimentar imaginarios que hagan muy difícil la práctica de la interculturalidad. Queremos analizar hasta qué punto nuestras ciudades globales se rigen aún por coordenadas locales y territoriales o si, por el contrario, la llegada de inmigrantes está trayendo consigo un nuevo concepto de ciudadano y de identidad cultural. Nos interesa, en definitiva, explorar qué modelo de identidad transmiten y consolidan los medios de comunicación y si éste sirve para fomentar el diálogo entre culturas o, por el contrario, está contribuyendo a perpetuar la brecha entre el "nosotros" y el "ellos".

Con ese fin, hemos llevado a cabo un Análisis Crítico del tratamiento verbal que se da a los inmigrantes en noticias procedentes de la prensa escrita española actual. Nos hemos centrado en las relaciones que se establecen en el espacio urbano, en la ciudad, en la medida en que es ahí donde se desarrolla la vida del inmigrante y donde se establece el contacto cotidiano con el resto de ciudadanos. Las noticias proceden de los diarios El País y $A B C$ del año 2009, año en el que la inmigración era considerada por los ciudadanos según los barómetros del CIS de junio de 2009 y enero de 2010-, la tercera preocupación en importancia, tras el paro y los problemas económicos. Las noticias fueron seleccionadas a partir de la búsqueda, en las hemerotecas digitales de ambos periódicos, de los conceptos inmigrante + inmigración + ciudadanía. El resultado fue un total de 68 noticias, 39 El País y $29 A B C$, en las que estos conceptos aparecían relacionados. Finalmente, extraeremos conclusiones en relación con la situación actual de la inmigración como fenómeno global y local en el mundo actual.

El concepto de "Representación social" (Pardo, 2007; van Dijk, 1990, 2008) nos permitirá delimitar qué clase de práctica social y verbal realiza la prensa y cuál es el 
conocimiento social que transmite. Se definirá a continuación el concepto de manipulación como actividad social, cognitiva y discursiva que encuentra en los medios de comunicación una de las principales vías de expresión. Metodológicamente, utilizaremos algunos conceptos de la Lingüística Sistémico Funcional (LSF) y del Análisis Crítico del Discurso (ACD) que permiten justificar la presencia de representaciones ideológicas en el discurso, sin perder las perspectivas lingüística y sociológica. Las bases teóricas sociológicas de este trabajo se sustentan sobre el desarrollo de los conceptos de globalización, inmigración e identidad. Se observará la estrecha interrelación de estos tres fenómenos y ello permitirá extraer conclusiones sobre su vigencia a partir de los datos extraídos de la prensa.

\section{EL LENGUAJE COMO PRODUCTOR DE REALIDAD: EL DISCURSO DE LA PRENSA Y LA MANIPULACIÓN DE LA INFORMACIÓN}

En efecto, uno de los papeles fundamentales del lenguaje y sus manifestaciones discursivas en las sociedades humanas es el de crear determinadas representaciones colectivas (J. Beriain) o sociales (van Dijk), esto es, proporcionar a quienes integran una comunidad formas de conocimiento y de interpretación del mundo. Las representaciones sociales o colectivas constituyen "estructuras intersubjetivas de conciencia" (Beriain, 1990:47), o lo que es lo mismo, el conocimiento institucionalizado y compartido que, como parte de una determinada comunidad, se aprenden e interiorizan a lo largo de la vida. La escuela, la familia, los medios de comunicación, el mercado, etc., se encargan de ir aportando ese tipo de información que está social y culturalmente condicionado y que cambia, por tanto, en las distintas etapas del acontecer histórico y social de una comunidad. Desde este punto de vista, podemos decir que mucha de la información social que asumimos y aprendemos no procede de experiencias personales, sino que nos llega a través de discursos. El término procede del ACD y de la formulación socio-cognitiva y discursiva que van Dijk viene haciendo hace tiempo del propio concepto de ideología. Las representaciones sociales o colectivas son el puente entre los grandes sistemas de creencias que suponen las ideologías y las actuaciones concretas de los individuos. Son, por tanto, generadoras y organizadoras del conocimiento social y se trasmiten de forma preferente a través de los discursos pues, como señala van Dijk (1990:166), "el discurso es de vital importancia en la expresión, comunicación y reproducción de las representaciones sociales".

La vinculación de los medios de comunicación con los sistemas de representaciones sociales o colectivas se evidencia aún más si consideramos, con Ariño (1997), Pintos (2005) y Pardo (2007), que, discursivamente, estas representaciones sociales colectivas se manifiestan de manera particular en lo que Pardo denomina "Temas". Los Themata se definen como los formatos representacionales más genéricos y consisten en aquello de lo que se habla. Son, en palabras de la autora, "los temas que dominan épocas, que ejercen influencias, que identifican a pueblos y a hombres" (Pardo, 2007:87). Estos temas (Ariño, 1997:210) constituyen, sin lugar a dudas, los signos ideológicos sobre los que giran los significados (Raitier, 2008:20). En este sentido, textos como los periodísticos, que trasmiten significado sobre el mundo real desde una posición privilegiada, pueden considerarse paradigmáticos del modo de construir y trasmitir el conocimiento social en una comunidad. Además, como señala de Aguinaga (2000:320), forma parte de la 
naturaleza misma de la disciplina periodística la selección de aquellos asuntos que identifican y definen un determinado momento social y la inmigración puede, sin duda, considerarse como uno de esos temas dominantes:

"El Periodismo es efectivamente una emanación de la sociedad, un modo de narrar los acontecimientos, una circulación de opiniones, un sistema de expresión espontánea regulador de las expresiones orgánicas, un poder vigilante de los poderes, una residencia de la literatura urgente, un instrumento de la política, una historia cotidiana, un género de conocimiento universal, una satisfacción del ansia de comunicación y tantas otras definiciones formuladas o por formular; pero todas ellas tienen el mismo fundamento y el mismo método: la clasificación (de Aguinaga, 2000:319).

En efecto, el Periodismo, como método de interpretación de la realidad, se sostiene sobre dos operaciones clasificatorias, la selección y la valoración, y dos factores que las justifican, el interés y la importancia. La selección consiste en establecer qué hechos serán difundidos por un medio determinado y, en consecuencia, cuáles -todos los demás- no van a obtener esa difusión. La valoración, por su parte, consiste en determinar cómo se van a difundir los hechos seleccionados, ya que la difusión, tanto en su dimensión cuantitativa como en la cualitativa, puede realizarse de muy diversas formas, y grados, desde el más ínfimo al más relevante jerárquicamente. El hecho, pues, de que un asunto sea elegido como noticia da cuenta de la notabilidad con la que se aborda una determinado acontecimiento o tema. Sin embargo, no debemos olvidar que entre el acontecimiento en sí y su conversión en noticia media un hecho fundamental que es su conversión en discurso: “[...] El lenguaje -señala Gomis (1987:22)- es el modo de captación de la realidad que permite darle forma, aislar dentro de ella unos hechos a los que, por un procedimiento de redacción, se convierte en noticia".

Es, precisamente, en ese proceso de verbalización de la realidad en el que ésta puede convertirse en signo ideológico. Al respecto, señala Martínez Albertos (2004:45) que el hecho mismo de, necesariamente, tener que separar y aislar unos datos dentro de un continuum para elaborar la noticia, supone ya un cierto grado de manipulación. Ciertamente, en un sentido estricto de la palabra, se manipula cada vez que se maneja o se elabora algo, y, si aplicamos el concepto al ámbito de la comunicación informativa, eso es lo que con seguridad ocurre en el día a día de la actividad periodística. Pero la manipulación puede entenderse también, en un sentido intencionadamente ideológico, como "el ejercicio de una forma de influencia ilegítima por medio del discurso: los manipuladores hacen que los otros crean y hagan cosas que son favorables para el manipulador y perjudiciales para el manipulado" (van Dijk, 2006:51). Estamos ante la manipulación como un acto social, como el ejercicio de la dominación y control en términos de pertinencia de grupo, posición institucional, profesión etc. con los que se define el poder de los grupos o sus miembros. Así, "la manipulación, socialmente, es una forma discursiva de reproducción del poder de la elite que va en contra de los intereses de los grupos dominados y reproduce la desigualdad social" (van Dijk, 2006:54).

Evidentemente, el discurso de la prensa es una fuente para la reproducción social de este poder que puede facilitar los intereses ilegítimos de los dominantes.

Pero la manipulación es también una actividad cognitiva, puesto que influye en las ideas y conocimientos de los receptores y repercutirá sobre sus acciones sociales. Según van Dijk (2006:54 y ss) -cuyo trabajo sobre manipulación y discurso estamos siguiendo-, 
el discurso manipulativo involucra el procesamiento de la información en la memoria de corto plazo (MCP), que tiene que ver con la comprensión inmediata de palabras $u$ oraciones. En las noticias, por ejemplo, los titulares realizan esta función y provocan que los lectores presten atención a cierta información más que a otra. La manipulación relacionada con la memoria de largo plazo (MLP) es más estable, y es la que permite "la construcción de modelos mentales en la memoria episódica, que incluyen nuestras propias opiniones y emociones asociadas con un nuevo oído o leído" (van Dijk, 2006:57). Son estos modelos los que utilizamos para procesar los conocimientos, compartirlos y comunicarlos. Así, quien ejerce la manipulación -un medio de comunicación, por ejemplolo que quiere conseguir es condicionar y limitar el proceso de comprensión o interpretación de los lectores a favor de sus intereses. Es en la MLP donde se almacenan las creencias socialmente compartidas, permanentes y estables a las que denominamos representaciones sociales o colectivas.

Señala van Dijk (2006:63) que los dos procedimientos más habituales para ejercer la manipulación son: a) La estrategia emocional, que consiste básicamente en la autopresentación positiva de Nosotros/Presentación negativa de los otros; y en la repetición de mensajes y sucesos relacionados; b) el proceso de Generalización, que trata de difundir conocimientos y actitudes que se presentan como la opinión más aceptada por una comunidad.

La estrategia principal para manipular es, pues, la de una auto-presentación positiva y una presentación negativa de los otros que permite mostrar los hechos a favor de los intereses propios, mientras que se culpa de estos y de situaciones negativas a los oponentes o los otros.

De todas formas, estas estrategias discursivas y los patrones de polarización ideológica no se cumplen simplemente por el hecho de utilizarlos sino que, en los receptores, tiene que faltar algún tipo de la información y de recursos con respeto al tema para poder ser víctimas de manipulación ideológica. "En resumen -señala van Dijk (2006:65)- la estrategia general del decurso manipulativo consiste en enfocar discursivamente aquellas características sociales y cognitivas de los receptores que los hacen más vulnerables, menos resistentes a la manipulación, que los hacen crédulos y víctimas dispuestas a aceptar creencias y hacer cosas que normalmente no harían”. A través del análisis, pensamos que se hace evidente la no neutralidad de los discursos y, por tanto, su potencialidad como objetos del poder en la escena social; antes, sin embargo, es necesario definir qué supone el fenómeno migratorio en un mundo globalizado para poder así comprender la reconceptualización de términos como identidad y territorio, esenciales para entender el tratamiento que la prensa española actual hace de ellos.

\section{LAS MIGRACIONES EN EL CONTEXTO DE LA GLOBALIZACIÓN}

Existe un evidente grado de incomprensión acerca de lo que representa la globalización, confundida generalmente con el globalismo relacionado con el neoliberalismo y con la dimensión exclusivamente económica (Giddens, 2003:23; Beck, 2002:27-127; Safranski, 2004:19 ss.; García-Canclini, 2001:29). Pero también es verdad que la globalización concentra la mayoría de sus procesos en la economía y lo hace sobre todo en la región atlántica norte y, en menor medida, en Japón y China (Sassen, 2007:15 y 75 ss.), por lo que no puede decirse que se haya implantado en la totalidad del planeta ni que se haya 
universalizado su idea (García-Canclini, 2005:12; Beck, 2002:166). A ello hay que sumar que está afirmando o agudizando las profundas diferencias económicas y sociales entre continentes, naciones, regiones y ciudades (Abad, 2005:19) y, correlativamente, que está "fronterizando" el planeta (Arango, 2003:10), en la medida en que los Estados territoriales se mantienen tercamente cerrados en un sistema mundial cada vez más abierto (Malgesini, 1998:33; Portes y otros, 1998:69). Además, debido al carácter inherentemente polarizador de la expansión capitalista mundial, se han agravado también las contradicciones del capitalismo, incapaz de solventar la tensión existente entre la gestión económica, cada vez más mundializada, y la política y social, todavía fragmentada en naciones diferentes.

En consecuencia, la globalización ha dado lugar al resurgimiento de los nacionalismos y de las luchas sociales, así como el auge de la etnicidad, una respuesta política a la globalización económica (Amin, 2002:38 y 75-95). Igualmente ha generado un cierto malestar (Stiglitz, 2003:30 ss.) y ha conducido a que las migraciones se vean más como problema que como una posibilidad de desarrollo económico, social y cultural. Aunque esta problematización no es tanto el resultado del fracaso de la globalización como de la ineficacia de los acuerdos sociales, políticos y económicos (Sen, 2007:166) y del escaso papel conferido a la sociedad y a la ciudadanía mundial (Beck, 2002:32 ss.). Así, se ha evidenciado más que nunca la necesidad de una política global (Bauman, 2004:31), de un cambio en la gobernanza para que funcione la globalización (Stiglitz, 2003:282) y de una ética global (Safranski, 2004:58; Bauman, 2004:28).

Como se verá más adelante, los medios de comunicación escritos, están lejos de llenar el vacío de la ética global, observando las migraciones como un problema y convirtiéndose en un mero reflejo acrítico del miedo a lo global.

\subsection{La otra cara del capitalismo global: la transnacionalización de la mano de obra}

Es sorprendente si se tiene en cuenta que la globalización no es una maldición y representa un factor de progreso en la historia (Sen, 2007:171 ss), que provoca múltiples flujos económicos, financieros, tecnológicos, culturales, sociales, comunicacionales y humanos y que afecta, sí, a acontecimientos e instituciones, pero también a nuestra vida cotidiana (Giddens, 2003:16). Además, los flujos migratorios están profundamente conectados con los demás y, especialmente, con los comunicativos, económicos y financieros y, por tanto, la migración y la globalización caminan juntas.

En efecto, desde 1980, las migraciones se producen en un nuevo contexto internacional impulsadas, ante todo, por la ampliación de la magnitud del mercado global de capitales que produce una de las más llamativas paradojas de la globalización, en tanto que la extensión de la actividad económica supone una fuerza centrípeta que estimula la concentración y, con ella, una fuerza centrífuga (Florida, 2009:29). Y es que la economía global presenta una gran dispersión y movilidad geográfica $\mathrm{y}$, simultáneamente, una concentración territorial de los recursos para la gestión y la prestación de servicios. Por tanto, cuanto más se globalizan las empresas, más crecen sus funciones centrales de gestión (Sassen, 2007:80 ss.) y más ayudan a que las ciudades donde se instalan asuman la etiqueta de "global". Específicamente, para que una ciudad alcance la definición de global debe poseer centros financieros, la presencia de sedes corporativas internacionales, el desarrollo de servicios de gestión empresarial y comercial, centros manufactureros, un bien desarrollado nudo de transportes, una concentración de elites artísticas y científicas, un turismo internacional, un tamaño considerable de población y una mezcla multicultural de habitantes nacionales y extranjeros (García Canclini, 2005:167). En el pleno sentido de la 
expresión, en España es posible que únicamente Madrid y Barcelona puedan ser clasificadas como globales, si bien otras muchas urbes acogen en su seno alguno o varios de los elementos que caracterizan esta globalización. Y, en todo caso y especialmente en los años anteriores a la crisis, numerosas ciudades de nuestro territorio -especialmente de Madrid, Cataluña, Comunidad Valenciana, Baleares y Murcia- han acogido en su seno importantes remesas de inmigrantes, uno de esos factores destacados de la globalización.

De este modo, en las ciudades globales o que disponen de un importante porcentaje de población de origen extranjero, lo global se interioriza en lo nacional, lo habita, y, al mismo tiempo, trasciende el Estado-nación (Sassen, 2007:8-11). En consecuencia, la globalización y la localización constituyen dos fenómenos parejos y profundamente interrelacionados (Moreno, 2005a:84) y, hasta tal punto esto es así, que, ciertamente, para la mayoría de los asuntos o problemas con los que se enfrenta el mundo contemporáneo, y los migratorios no son los menos importantes, no existen soluciones locales para problemas globales (Bauman, 2004:30), como tampoco son suficientes, en muchos casos, las intervenciones estatales.

Por todo lo que acabamos de decir, la otra cara del capitalismo global, de la internacionalización de los flujos comerciales y de capital, es la transnacionalización de la mano de obra (Sassen, 2007:157 ss.), caracterizada por una serie de llamativas contradicciones (Roche y Serra, 2009:35-6), entre las que destaca el que las migraciones, al dirigirse fundamentalmente a las ciudades globales, constituyen tanto un fenómeno global como local. Desde este último aspecto, parece obvio pero conviene recordarlo frente a posiciones excluyentes o racistas, las personas que se instalan aquí son nuestros vecinos del piso de arriba, las madres de nuestros hijos, nuestros tenderos y médicas, nuestros futuros representantes políticos $\mathrm{y}$, tal vez también, las próximas presidentes de nuestros gobiernos. Y, en cualquier caso, en el plano cultural, introducen nuevos comportamientos, hábitos y pautas de consumo que transforman hondamente las culturas locales y sus estilos de vida (Lacomba, 2005:159).

\section{IDENTIDAD Y MULTICULTURALISMO}

El plano cultural al que acabamos de referirnos se convierte en el terreno de batalla de la ideología interna del sistema mundial moderno, en la medida en que -como hemos dicho- la actividad económica y las migraciones se vinculan inseparablemente. Al respecto, piensa I. Wallerstein que la contradicción entre nacionalismo e internacionalismo es inherente a la lógica del sistema capitalista (Wallerstein, 2007:193 ss.). Ello porque la propia cultura es tanto particularista - "capacitadora" o "autoafirmativa"- como universalista- "restrictiva" o "reguladora y normativa" (Bauman, 2002:19-20), porque la reivindicación de la singularidad forma parte del juego político del sistema mundial y porque desempeña un papel fundamental en el funcionamiento de dicho sistema. La tensión nacionalismo-internacionalismo constituye, pues, el marco cultural dentro del que opera el sistema mundial (Wallerstein, 2007:218 ss.) y, consecuentemente, el multiculturalismo de las grandes ciudades forma tan parte de ese fenómeno económico global como el mercado financiero internacional (Sassen, 2007:126).

Sin embargo, quizás no estemos reflexionando adecuadamente y con el rigor que sería necesario; es más, parece que los movimientos migratorios dirigen a las sociedades $-\mathrm{y}$ a los medios de comunicación- en una dirección contraria a ellos y, por tanto, a lo que sería 
de desear, ya que hoy el sentido de los otros se pierde y se exacerba a la vez. Esto se relaciona con la crisis de la identidad que produce procesos generadores de alteridad (Augé, 1996:11 ss.), la ilusión acerca del destino común, la violencia disgregadora (Sen, 2002) e, incluso, identidades asesinas (Maalouf, 2004). Por eso, conviene inquirir nuevamente y con más intensidad si cabe, acerca de lo que significa hoy la identidad y, desde ésta, de qué manera contemplamos la posible inserción de los inmigrantes.

En síntesis, pueden señalarse algunos elementos caracterizadores de la identidad (Roche y Serra, 2009:41 ss.). Ante todo, la modernidad supone el paso de la identidad cerrada y limitada del mundo antiguo a otra exteriorizante, expansiva y sin fronteras. Por otra parte, la secularización del mundo moderno ha emplazado al individuo a olvidar los viejos sustentos exteriores metafísicos y absolutos y a apoyarse en sí mismo, pero este tipo de individuo se encuentra en conflicto con el exterior - con el mundo y la sociedad- y con su interior donde, inclusive, se produce una auténtica guerra civil -Kant, Hegel y Freud-. Así, la identidad actual es más aleatoria, proteica e inestable, de modo que no nacemos en una identidad fija e inmutable sino que la construimos, la convertimos en un proyecto inacabado. Como consecuencia, la mutabilidad se convierte en un signo de la identidad, las identidades colectivas devienen más camisas que piel, es decir, que son opcionales y no ineludibles y, finalmente, el tiempo no es el enemigo de la identidad sino su condición. De la misma manera, la identidad es más consumida que producida y más plural que única, de modo que todos nos convertimos en individuos que han perdido una sustancia identitaria, sustituida por otra comprada, y todos estamos involucrados en identidades de diversas clases y en contextos dispares. Ello obliga a una dosificación, a seleccionar o escoger razonadamente frente a la imposición de identidades singulares $\mathrm{y}$, sobre todo, exige elegir y situarse ante el desgarro o ante la reducción de nuestra compleja identidad a una singular que conlleva sectarismo, intolerancia o, en el caso más extremo, un tipo de identidad asesina (Maalouf, 2004:10). Finalmente, parece que no queremos tomar conciencia de que el Otro es siempre una proyección, el rechazo o la negación de una parte del Yo (Nair y otros, 1999: 125). Y, sobre todo, que la identidad está relacionada con la alteridad, que es su complemento (Sartori, 2003:48), lo que quiere decir que la personalidad individual se conforma entre el ser y la relación (Augé, 1996:24).

Con todo lo que se acaba de señalar, parece obvio que la globalización nos obliga, también a los medios de comunicación, a pensar el multiculturalismo, la otra cara de la globalización, primero que nada porque promociona la diversidad como valor en sí mismo (Sen, 2007:2012), porque constituye "una idea guiada y construida por el compromiso con la defensa de la libertad individual y la igualdad" y porque, entre otras cosas, rechaza una idea del Estado o de la ciudad como perteneciente al grupo dominante (Kymlicka, 2009:15 y 80 ss.).

La necesidad de examinar el multiculturalismo se hace más perentoria y urgente si cabe, por cuanto que la realidad parece caminar por senderos difíciles y llenos de incertidumbres, miedos y amenazas. Primero porque la globalización está extremando la tensión entre los intereses de los individuos y el de las sociedades organizadas en ciudades, en nacionalidades o en Estados (López, 2005:17). Segundo porque los principales modelos migratorios (López, 2005:77; Moreno, 2005:137 ss.; Nair, 2006:91 ss.) que los Estados han impulsado para enfocar adecuadamente los asuntos migratorios se encuentran hoy en una profunda crisis de legitimidad: el "exclusivo" (Japón y Alemania), porque no admite nunca en su seno a los inmigrantes y, en consecuencia, porque no termina integrándolos social y políticamente; el "asimilador" (Francia), porque las recientes revueltas de la banlieu parisina y de otras ciudades han evidenciado el fracaso del modelo, la no 
integración de los marginados inmigrantes que, a pesar de ser considerados franceses, no han obtenido la igualdad de derechos económicos y sociales; y, por último, el "multicultural" (USA, Gran Bretaña, Canadá, Australia, Nueva Zelanda y Holanda), porque los atentados de Londres del 2005, el asesinato del cineasta Theo Van Gogh en Holanda y la reclamación de la Sharía en Canadá han revelado que algo no funciona bien en este paradigma ( $\sin$ olvidar que Angela Merkel y David Cameron lo han dado por muerto). Quizás, porque no tiene en cuenta que la nación o la ciudad son un conjunto de ciudadanos y no una colectividad formada por identidades étnicas o religiosas y, posiblemente, porque no distingue el multiculturalismo del "monoculturalismo plural" que constituyen dos culturas cercanas pero separadas sin acercamiento alguno en guetos urbanísticos, sociales, económicos y culturales (Sen, 2007:209 ss.).

Ante este panorama, el modelo "intercultural", quizás, puede representar una alternativa viable, en la medida en que, aunque no ha sido implementado por ningún estado, ya cuenta con una cierta experiencia, sobre todo, en el mundo educativo y porque se basa en dos interesantes conceptos (Sartori, 2003:33-6; Maalouf, 2004:50: el de reciprocidad -que exige a los inmigrantes y a la sociedad de acogida la exigencia de construir una cultura y un código normativo común (Nair y otros, 1999:197)- y el de interrelación o diálogo -que activa el respeto mutuo entre los inmigrantes-.

Ahora bien, ciertamente, el diálogo no es fácil. En primer lugar, porque en las ciudades globales lo que no queda sujeto a la globalización, lo identitario particularmente, o se desprecia o se minusvalora. En segundo lugar, porque se va a hacer cada vez más difícil obviar los derechos individuales y colectivos, la identidad individual y la sociedad multicultural $\mathrm{y}$, en consecuencia, porque deberemos tener en cuenta, con la dificultad que ello trae aparejada, los dos derechos simultáneamente (Beck, 2006:2). En tercer lugar, porque desde las ciencias sociales sabemos bien que en todo diálogo intercultural atronan dos ruidos sociológicos difíciles de apaciguar: la jerarquía de las culturas que se consideran más poderosas que otras y aquellas que, por el contrario, se sienten injustas víctimas de la historia. Ante tal constatación, una posible medicina puede ser el contrarrestar la jerarquía del diálogo intercultural con una corrección ética que escuche con especial atención y sensibilidad al más débil, pero, eso sí, intentando evitar que éste caiga en el victimismo y tratando de que tome conciencia de la necesidad de abrir al mundo lo propio, sin complejos de inferioridad. Y, en cuarto y último lugar, porque debemos pasar de la alteridad a la identidad (Malgesini, 1998:28), tarea de una extrema complejidad si tenemos en cuenta que, históricamente, solo han existido dos estrategias tradicionales para enfrentar la otredad: "vomitar" a los otros, ubicarlos en guetos, exiliarlos o aniquilarlos; y "devorar" los cuerpos extraños para convertirlos en un cuerpo idéntico, en nuestro cuerpo, pero a costa de la desaparición de la otredad (Claude Lévi-Strauss, Tristes tópicos, 1988).

Como se va a comprobar, la difícil tarea a la que nos estamos refiriendo todavía se presenta más imposible porque los medios de comunicación escritos inconscientemente caen en la estrategia del vómito.

\section{LOS CONDICIONANTES ESPACIO-TEMPORALES DE LAS MIGRACIONES GLOBALES}

Lévi-Strauss vincula a los otros con el cuerpo, el centro neurálgico del espacio, e igualmente cuando nos referimos a la globalización, a las ciudades globales o a las 
migraciones lo hacemos en clave de conceptos espaciales, aunque -como ya hemos indicado anteriormente- en el momento en el que ni siquiera la "globalización" se ha vuelto "global" algo está fallando en el espacio, o más bien en la construcción que del mismo hacen las sociedades contemporáneas. Desde esta perspectiva, quizás debamos tener en cuenta que la dimensión temporal también determina las migraciones globales. Sobre todo, porque en la sociedad y en los individuos ha triunfado el devenir (Baumer, 1985:379 ss.) y porque el mismo espacio ha sido afectado por el tiempo de tal manera que aquél ha quedado comprimido, reducido o aniquilado por éste (Roche y Serra, 2009:45-6). Ello trae consigo efectos existenciales y sociales, institucionales e individuales. El influjo del tiempo, por ejemplo, ha llevado a que el sistema capitalista sea mucho más dinámico que antes, a que solucione sus problemas de producción y de distribución de una manera dinámica y no estática (Heilbroner y Milberg, 1999:46 ss y 154) y, en suma, a que se caracterice por la flexibilidad, la ligereza, la fluidez, el desarraigo, el azar, el caos, la inestabilidad, el nomadismo y la movilidad (Roche y Serra, 2009:46 ss.).

El fluido y dinámico contexto económico en el que se desarrollan las migraciones ha conducido a que éstas estén más condicionadas por el movimiento que por el asentamiento (Sennet, 2006:10; Mendoza, 2004), a lo que hay que añadir que últimamente se han acelerado (López, 2005:16) y que la condición del inmigrante está en constante mutación y negociación de su identidad (Nair, 2006:212). Además, en la medida en que el ritmo frenético de las mercancías y del consumo se ha impuesto como paradigma de los hechos sociales, es decir, en tanto que el tiempo de la mercancía constituye el modelo de las relaciones sociales (Sánchez Capdequí, 2004:300), de la existencia social y de la vida humana (Steingress, 2007:189 ss.), los inmigrantes han sido transformados igualmente en valor de cambio, en una mercancía más puesta en venta (Nair, 2006:169). Finalmente, este continuo y acelerado devenir de los hechos sociales, de la economía y de los fenómenos migratorios dificulta en extremo la asimilación de la conciencia humana, cuyo tiempo biológico es más lento, por lo que no debe sorprendernos la perplejidad con la que los ciudadanos y los medios de comunicación observan y acogen las migraciones, como tampoco puede asombrarnos que estas últimas escriban sobre las migraciones cuantificándolas más que cualificándolas.

Por otra parte, el espacio se ha visto afectado por el tiempo, ya que estamos asistiendo a una cierta relativización del espacio físico, a una deslocalización, a una invisibilidad social creciente y a una virtualización de todo lo que queda bajo la órbita espacial. Los propios inmigrantes, mediante las nuevas tecnologías, relativizan las distancias entre su país de origen y el de acogida (Viruela, 2007:274) y deslocalizan sus movimientos (González, s.a:101 ss.). Además, los suburbios donde viven se han convertido en espacios vacíos de significado porque en ellos las clases medias no entran y, por tanto, no existen, quedan invisibilizados. Junto a ellos, están los no lugares, sitios de la circulación, de la distribución y de la comunicación donde los inmigrantes, como los autónomos, no poseen ni identidad, ni historia, ni relación (Augé, 1996:98). Y qué decir de la creación, por parte de los inmigrantes, de espacios imaginarios -el Carnaval de Londres o la Feria de Abril de Barcelona- en los que los ya no se sienten ni del lugar de donde proceden ni del que les acoge, sino de un espacio imaginario ubicado en un lugar inconcreto (Bauman, 2003:211; Bauman, 2004:145 ss.). Finalmente, internet y las nuevas tecnologías han permitido las comunicaciones entre los inmigrantes y sus familiares y los han ubicado en ese mundo virtual que éstas generan. 
Estos nuevos espacios han instaurado redes que trascienden los territorios, pues vinculan dinámicamente las poblaciones de las sociedades emisora y receptora (Gurak y otros, 1998:76-7). Asimismo, han establecido relaciones translocales y transnacionales que traspasan las fronteras del espacio físico y social (Solé y otros, 2006:21), de modo que estas redes han llevado al inmigrante a "marcharse sin irse del todo", a partir físicamente pero no socialmente, lo que ha dado lugar a la transnacionalidad o binacionalidad (Aparicio, 2001:14 ss.). Y, a la inversa, han conducido al inmigrante a quedarse sin quedarse del todo, a no participar activamente en la sociedad de acogida y a habitar en un lugar sin cuerpo y en un tiempo meteórico.

Como se comprobará más adelante, los medios de comunicación escritos, reflejan esta situación, desubicando a los inmigrantes del espacio y ayudando a disolver esta categoría tan esencial para el fenómeno migratorio.

Todo ello ha tenido también su efecto y su consecuencia en la crisis de la ciudadanía, un término nuevamente espacial que está vinculado con la ciudad. Y es que la entrada masiva de inmigrantes, al no obtener los mismos derechos que los ciudadanos de los países de destino, ha encogido el concepto de ciudadanía, situándolo a la baja o creando una escala jerárquica de gradaciones que sitúa en primer lugar a los nacionales, en segundo a los naturalizados, en tercero a los denizen o residentes indefinidos, en cuarto a los temporales y, finalmente, a los irregulares (Arango, 2003:19). Por lo demás, estas corrientes migratorias han enfrentado al viejo orden de derecho internacional -basado en la mirada nacional y apoyado en los principios de colectividad, de territorialidad y de fronteras- con el nuevo orden del derecho humano -fundado en la mirada cosmopolita y en el individuo como titular de los derechos subjetivos- (Beck, 2005:169). Esto explica que las migraciones hayan cuestionado profundamente la visión que vinculaba a la ciudadanía al estado-nación (Ugur, 1998:329), ya que la ha contrapuesto a los derechos del hombre, que son universales (Nair y otros, 1999:91). Por tanto, ello nos obliga a desarrollar un nuevo tipo de ciudadanía que concilie lo local (el oikos) y lo global (el ágora).

Sin embargo, como veremos, los medios de comunicación escritos, sin ni siquiera tener en cuenta el concepto de ciudadanía, han reducido al inmigrante a tales niveles de no existencia que hace muy difícil a los componentes de un grupo social identificarlos como miembros suyos.

\section{LA CIUDAD Y LOS INMIGRANTES: ANÁLISIS Y RESULTADOS}

No hay duda de que la prensa, como género discursivo cuyo propósito es proporcionar información a una comunidad lingüística y social, contribuye de forma radical a crear en los miembros de esa comunidad un tipo de representación social del inmigrante y/o la inmigración y de su participación en la vida y en el espacio ciudadano. Como señalábamos al principio, la búsqueda en los diarios El País y $A B C$ del año 2009 introduciendo los conceptos inmigrante, inmigración y ciudadanía dieron como resultado un total de 68 noticias (39 El País y 29 ABC) en las que estos conceptos aparecían relacionados. Lo que aquí presentamos forma parte de un trabajo más amplio en el que estamos analizando cómo el lenguaje crea significados sociales a través del uso de determinadas opciones semánticas y léxico-gramaticales que pueden interpretarse como la expresión de un determinado punto de vista social sobre el objeto. Vamos a centrarnos ahora en algunos aspectos de la expresión de lo que denominaremos el "significado experiencial" (Eggins, 
2003:40) por ser el más adecuado a nuestros objetivos. El significado experiencial es utilizado por los hablantes para construir "la naturaleza de la acción social que está ocurriendo" (Eggins y Martin, 2003:186) y tiene que ver, precisamente, con la representación de la realidad, es decir, con quién hace qué, a quién, cuándo y dónde. Esto ocurre, entre otros, a través la selección léxica y distintos recursos léxicos de la lengua, como nominalizaciones o uso del lenguaje figurado. El significado experiencial nos permite definir a los actores del discurso -quiénes son- y concretar sus acciones -qué hacen, dónde lo hacen-. Definir a los sujetos y sus actos nos sitúa, además, ante las dos estrategias clave para la manipulación ideológica de los discursos: la de generalización y la de presentación positiva de nosotros y negativa de los otros.

En efecto, uno de los recursos más evidentes para establecer la diferencia nosotros/los otros consiste en la utilización de léxico de polaridad negativa para caracterizar todo lo que rodea al sujeto, en este caso, a los inmigrantes. En el siguiente cuadro hemos introducido léxico extraído de las noticias seleccionadas y organizado a partir de los tres tipos de significados experienciales: quiénes son los inmigrantes, qué hacen y dónde viven. No presentamos datos estadísticos sino sólo una muestra suficiente y significativa para comprobar si, en efecto, dicha estrategia discursiva se cumple.

\section{Quiénes son}

Sustantivos: Víctima, ilegal, inmigrantes, extranjeros, jóvenes inmigrantes sin familia, clandestino, indocumentado; interpol, crisis, pateras, radares, cuevas, colonia, gueto, violencia, problemas, delito, derechos, mafia, paro, desempleo, centro de acogida.

Nominalizaciones: Irrupción, detención, población inmigrante, reagrupamiento, expulsión, agresión, estigmatización, impacto, identificación, preocupación, sin solución, destrucción, falsificación, acciones jurídicas, criminalidad, control, brote xenófobo, disimilitud, aislamiento, reinserción, retorno, integración, adaptación, regularización,

Adjetivación: llegada, [mujeres inmigrantes] maltratadas, detenidas, desorientados, liberados, segregados, extracomunitarios, falsos ciudadanos; algunos, los más visibles, violentos; acogidos, irregulares, esclavos, víctimas; frenazo, recorte, muerte, ubicado, abandono, oleada, [instalación] semicarcelaria.

Cuantificación: fuerte aumento en el número; 371 en 2008 frente a 225 en 2007; 230 bajo tutela; oleadas de chavales de golpe; sólo 13 inmigrantes, una decena de inmigrantes, más de 7.000 inmigrantes, la cifra de inmigrantes, el número de inmigrantes, en total, la mayor parte de los inmigrantes, el 63\% del alumnado hijo de inmigrante, más de la mitad de los hijos de los inmigrantes, el $6 \%$ de los inmigrantes, gran número de inmigrantes, más de 50.000 son inmigrantes, mucha presencia de inmigrantes, el conjunto de inmigrantes, un tercio, multitud de problemas, (masiva) llegada, demasiados, bastantes inmigrantes.

\section{Qué hacen}

Verbos: en busca de una vida que su país no puede darles; protagonizan episodios violentos; agresiones sexuales; recurrentes agresiones; duermen en el suelo; devastador consumo de disolvente para drogarse, crean alarma social [...] que destrozó el trabajo educativo y ahondó la brecha entre estos jóvenes y la sociedad de acogida; los vecinos hicieron público su malestar, [la inmigración] destruye. Sufren, no quieren retornar, elevan el PIB, viven en cuevas, no llegan, quieren pasar inadvertidos, comenten delitos; esfuerzos de integración; muchos participan en las comparsas de carnaval; algunos incluso tienen novia; imaginan su vida a este lado del estrecho, escriben en la ciudad. Acciones 
relacionadas con los inmigrantes: repartir a los alumnos inmigrantes, renunciar, ser ubicado, endurecer, impulsar, interesarse, ayudar, sorprender, asignar plazos, poner orden, disparar, hipotecar.

\section{Dónde viven}

Espacio cualitativo: En el centro histórico: degradado, colonizado, ocupado con colonias (chinas), en el que "irrumpen"

Espacio cuantificado: En los límites: en pisos, en barrios, en polígonos, en el "sur" o en el "norte" (polaridad), en la periferia

Espacio incomunicado: En no lugares: albergues sociales, centros, residencias, lugares de acogida, instalaciones semicarcelarias, aulas "segregadas"; Centro de menores: el más conflictivo, calificado de "potencialmente explosivo", en el centro de Tolosa, tiene los días contados, provisional, cerrará, serias deficiencias, preocupante nivel de deterioro, fracaso, viven 48 en un lugar para 20; nuevo centro serán ubicados en un nuevo edificio en Maturene; en una zona muy alejada del centro de la ciudad.

Para situarnos en la ciudad, espacio que hemos tomado como punto de partida para este análisis, vamos a partir de una definición sencilla, la que proporciona el DRAE 2002 y que la identifica como "Conjunto de edificios y calles, regidos por un ayuntamiento, cuya población densa y numerosa se dedica por lo común a actividades no agrícolas". Una ciudad es, pues, primeramente, un lugar "en donde", que, como tal, se define por sus partes. Atendiendo a las metáforas espaciales habituales, éstas se distribuyen como: dentro/fuera, centro/periferia, arriba/abajo y, su correspondiente, norte/sur. Desde este punto de vista, se establece una clara división centro/periferia en cuanto a la situación de los inmigrantes en la ciudad. El centro de la ciudad es el espacio que ocupan sus habitantes habituales, pero esa cualidad de centralidad ha perdido su valor simbólico cualitativo, al haberse establecido allí los inmigrantes y tal como se puede comprobar al observar el vocabulario con el que se expresa esta situación. Esto resulta especialmente evidente en una noticia aparecida el 31/01/2009, en El País, sobre el cierre de un centro de menores en Tolosa debido a que su presencia ha dado lugar a episodios violentos, alteraciones (ellos), rechazo vecinal y malestar por parte de los vecinos (nosotros) que sienten ocupado su espacio; los inmigrantes, en consecuencia, "serán reubicados" en una zona "muy alejada del centro", la periferia, que será el nuevo espacio que se les asigna. El espacio pues de los inmigrantes son los límites, las zonas que están más fuera que dentro, polares (en Madrid, es la zona o el "polígono" sur -una superficie de terreno delimitada para fines de valoración catastral, ordenación urbana, planificación industrial, comercial y residencial-), en Alicante, el norte; en definitiva, los extremos, los confines. De esta manera se establece claramente una división cualitativa dentro/fuera que sitúa a los inmigrantes en los márgenes de la ciudad -y, por ende, de la ciudadanía-.

En ocasiones, los inmigrantes se ubican en albergues sociales, centros, residencias, lugares de acogida, "instalaciones semicarcelarias", aulas "segregadas" que, en todo caso, son espacios aislados y separados. En el ejemplo del centro de acogida que señalábamos anteriormente, éste se califica de conflictivo, provisional, deficiente, etc..., constituye, pues, un espacio de aislamiento y de degradación; es lo que se denomina, un "no lugar" cuya naturaleza indefinible se verá incrementada con el traslado a la periferia. Estamos, pues, ante espacios de incomunicación con la ciudad, resguardados, ¿pero para proteger a quién de quién? Para protegernos a nosotros (los que somos de aquí) de los otros (que están aquí, pero que -como vamos a ver- no son). 
Como señala la definición, además de por las calles y los edificios, la ciudad se identifica por sus habitantes. Ser habitante de una ciudad es ser un ciudadano. Resulta curioso que en español se exprese lo que se puede considerar una característica transitoria -como se ha visto en la primera parte, la ciudadanía puede adquirirse y perderse, luego no es algo permanente, aunque el concepto de ius solis indica ser de algún sitio por haber nacido en él- como es la de tener la condición de madrileño o burgalés a través del verbo ser, que es el propio de la permanencia, y no el estar, que es el que indica los cambios: cuando te empadronas, adquieres derechos y deberes de un lugar y esto se manifiesta con el verbo propio de las características permanentes, pues decimos "Soy ciudadano alicantino" y no "Estoy ciudadano alicantino", aunque puedas dejar de serlo al cambiar de residencia. Sin embargo, esta es una explicación tramposa, porque en realidad usamos el verbo ser cuando predicamos una característica que el hablante piensa que en un momento concreto es identificadora -esta es la razón por la que muchos adjetivos admiten ambos (soy rubia, estoy moreno)-. Podemos decir, pues, que la ciudadanía, tanto en el sentido estricto como en el amplio referido a la nacionalidad, proporciona identidad: se es catalán, senegalés, murciano o marroquí.

En la prensa, independientemente de que los inmigrantes tengan los papeles en regla o que, al menos, estén empadronados -que es el requisito para la ciudadanía-, en ningún caso se les identifica con la ciudad de residencia sino con su identidad de origen. Se les nombra como ciudadano senegalés, marroquí, ecuatoriana...Más aún, el hecho de que se les denomine "jóvenes/menores extranjeros" (ellos) los define más por lo que no son -no son españoles (de los nuestros)- que por lo que los puede identificar como ciudadanos, transmitiendo así una idea de otredad y no de pertenencia que agranda las diferencias que el espacio había señalado.

En cuanto al quiénes son ellos, destaca el uso abrumador de léxico de polaridad negativa: "desorientados", "sin familia", "violentos"... En este tipo de enunciados el inmigrante, de forma activa o pasiva, aparece como creador de una situación o como víctima de ella: es siempre un problema. El uso de metáforas bélicas del tipo "estallar la polémica", "potencialmente explosivo" o "conflicto" no hace sino ahondar en la identificación del inmigrante con la conflictividad. Por otra parte, se da también en los medios periodísticos analizados una característica recurrente en los textos sobre inmigración: el uso constante de la cuantificación. Como se ha señalado, con mucha frecuencia las noticias sobre inmigración están llenas de información de cuantificación, de números que aumentan constantemente, dando a entender que es el exceso lo que provoca la conflictividad social (Rodrigo Alsina, 2007:12,44). En efecto, encontramos cifras concretas: 372 frente a 225, 7.000 inmigrantes, $80 \%$ proceden de Marruecos, etc... Igualmente, se usan verbos y expresiones con valor cuantificativo, "fuerte aumento", "oleadas de chavales", "incrementar"; y cuantificación indefinida, como "muchos", "algunos", "los demás", "bastantes", "demasiados", lo que da lugar a que se produzcan generalizaciones numéricas referidas a quiénes son ellos. Pero, bien sea desde la inconcreción o desde la precisión, el inmigrante aparece nombrado como un dato, de manera que a la pregunta de quiénes son ellos, la respuesta más inmediata sería: son muchos.

Por tanto, los inmigrantes son un conjunto numérico poco diferenciado aunque haya noticias sobre algunos colectivos particulares -chinos, marroquíes, latinos-. Esa falta de concreción se acentúa cuando se utiliza para nombrarlos el sustantivo abstracto "inmigración" que los despersonaliza y los convierte en un objeto sin posibilidad de acción o agentividad -capacidad de hacer algo-. Si a esto le unimos el hecho de que el concepto "inmigración" suele llevar unido como colocación la palabra "fenómeno", podemos 
afirmar que interesa más el acontecimiento que las personas que lo protagonizan. Los inmigrantes, así representados, no tienen carnalidad ciudadana y se caracterizan, de nuevo, por su no ser.

En cuanto al hacer de los inmigrantes, las noticias están mayoritariamente orientadas a mostrar la conflictividad. Los inmigrantes aparecen, por un lado, asociados al paro, las ayudas, el desempleo, luego, en realidad, no tienen ocupación; pero por otra parte, casi la única actividad que se enuncia de ellos es la delictiva: agresiones sexuales, consumo de drogas, episodios violentos. Se tratan todas ellas de actividades ilegales que vuelven a colocar al inmigrante fuera de la normalidad ciudadana. Como comenta Ortega Dolz (2007:8,259), el periodista aplica a la información sobre inmigración el esquema de lo noticiable y se busca lo impactante y novedoso a costa de crear estereotipos. Algunas noticias tratan, sin embargo, de mostrar la otra cara de este conflicto, lo que se evidencia a través de expresiones como "esfuerzos de integración", "participan en los carnavales", "incluso tienen novia", "escriben en la ciudad", que intentan compensar la dureza del léxico elegido para tratar la noticia.

\section{CONCLUSIONES}

Este análisis de la expresión verbal de la presencia de inmigrantes en nuestras ciudades a través de las noticias de la prensa, nos ha permitido observar algunos de los recursos que contribuyen a la construcción de determinados significados sociales a través del discurso:

-Mencionado preferentemente en relación con informaciones de cuantificación, el inmigrante es tratado como un dato numérico.

-La falta de concreción con respecto a su identidad lo convierte en alguien despersonalizado.

-La excesiva insistencia en su origen o en su no-origen, lo mantienen permanentemente como un extraño.

-A través del uso de léxico de polaridad negativa, el inmigrante es presentado como un problema, sea de forma activa o pasiva, como creador de una situación o como víctima de ella.

-Asociados a las ayudas, el desempleo, la delincuencia, el inmigrante es presentado como alguien que no tiene actividad o ésta no está permitida

-Los inmigrantes ocupan, en consecuencia, un no lugar porque, tal y como se presentan, ni "son" ni "hacen".

En nuestra opinión, los medios de comunicación escritos, al hacerse eco de los asuntos migratorios, podrían haber puesto más énfasis en reclamar más política global y más ciudadanía y podrían haber defendido o intentado llenar el vacío de la ética global, pero en su lugar han observado las migraciones como un problema y se han convertido en un mero reflejo acrítico de la defensa de lo local, del auge social de la etnicidad y, en suma, del miedo a lo global. Así, han situado a los inmigrantes en espacios marginales, descentrados y periféricos y, en definitiva, en "no lugares", desubicándolos del espacio y, de esta manera, ayudando a disolver esta categoría tan esencial para el fenómeno migratorio. Sin ni siquiera tener en cuenta el concepto de ciudadanía, pues, han reducido al inmigrante, ontológicamente, a un nivel de no existencia, de no ser, lo que unido a su marginación del espacio de la ciudad y a su desencarnamiento corporal, denota que la prensa española actual no es consciente de la fenomenología de los movimientos migratorios y, por el 
contrario, está contribuyendo a perpetuar estereotipos que quedan lejos del discurso intercultural que las sociedades actuales reclaman.

\section{BIBLIOGRAFÍA}

ABAD MÁRQUEZ, L. V. (2005), "Inmigración y cooperación al desarrollo", en Abad, L. V. y otros. Codesarrollo: migraciones y desarrollo mundial. Madrid: CYDEAL.

$A B C$, Hemeroteca digital, http://hemeroteca.abc.es/

AMIN, S. (2002), El capitalismo en la era de la globalización. Barcelona: Paidós.

APARICIO, R. (2001), Convivir como tarea. Nuevas demandas de la Sociología de las Migraciones. Madrid: Universidad Pontificia Comillas.

ARANGO, J. (2003), "Inmigración y diversidad humana. Una nueva era en las migraciones internacionales". Madrid, Revista de Occidente, 268.

AUGÉ, M. (1996), El sentido de los otros. Actualidad de la antropología. Barcelona: Paidós.

BAUMAN, Z. (2002), La cultura como praxis. Barcelona: Paidós.

-(2003), Modernidad líquida. Buenos Aires: FCE.

-(2004), La sociedad sitiada. Buenos Aires: FCE.

BAUMER, F. (1985), El pensamiento europeo moderno. Continuidad y cambio en las ideas, 1600 1959. México: FCE.

BECK, U. (2002), ¿Qué es la globalización? Falacias del globalismo, respuestas a la globalización. Barcelona: Paidós.

-(2005), La mirada cosmopolita o la guerra es la paz. Barcelona: Paidós.

-(2006), La sociedad del riesgo global. Madrid: Siglo XXI.

BERIAIN, J. (1990), Representaciones colectivas y proyecto de Modernidad. Barcelona, Anthropos.

DE AGUINAGA, E. (2000), Estudios sobre el Mensaje Periodístico, 6, pp.307-325.

EGGINS, S. (2002), Introducción a la lingüística sistémica. Logroño: Universidad de la Rioja.

EL PAÍS, Archivo digital http://www.elpais.com/archivo/

FLORIDA, R. (2009), Las ciudades creativas. Por qué donde vives puede ser la decisión más importante de tu vida. Barcelona: Paidós.

GARCÍA-CANCLINI, N. (2001), Culturas híbridas. Estrategias para entrar y salir de la modernidad. Buenos Aires: Paidós.

-(2005) La globalización imaginada. Buenos Aires: Paidós.

GHIO, E. y FERNÁNDEZ, M.D. (2008), Lingüística sistémico funcional aplicada a la lengua española. Santa Fe: Universidad Nacional del Litoral.

GIDDENS, Anthony (2003), Un mundo desbocado. Los efectos de la globalización en nuestras vidas. Madrid: Taurus.

GOMIS, L. (1987), El medio media, la función política de la prensa. Madrid: Seminarios y ediciones DL.

GONZÁLEZ RABANAL, M. C. (s.a.), "El control de las migraciones y la globalización de las economías ¿Fenómenos comparables? Madrid, Revista del Ministerio de Trabajo y Asuntos Sociales, 51.

GURAK, D.; CACES, F. (1998), "Redes migratorias y la formación de sistemas de migración”, en Malgesini, G. Cruzando fronteras. Migraciones en el sistema mundial. Madrid: Icaria-Fundación Hogar del Empleado.

HALLIDAY, M. A. K. (1982), El lenguaje como semiótica social, la interpretación social del lenguaje y del significado. México: Fondo de Cultura Económica.

HEILBRONER R. y MILBERG, W. (1999), La evolución de la sociedad económica. México: Prentice may.

KYMLICKA, W. (2009), Las odiseas multiculturales. Las nuevas políticas internacionales de la diversidad. Barcelona: Paidós. 
LACOMBA, J. (2005), "Marruecos, realidades de las migraciones y posibilidades del codesarrollo", en Abad, L. V. y otros Codesarrollo, migraciones y desarrollo mundial. Madrid: CYDEAL.

LARIO BASTIDA, M. (coord.) (2007), Medios de Comunicación e Inmigración. Murcia: CAM.

LÉVI-STRAUSS, C. (1988), Tristes trópicos. Barcelona: Paidós.

LÓPEZ SALA, A. M. (2005), Inmigrantes y Estados, la respuesta política ante la cuestión migratoria. Barcelona: Anthropos.

MAALOUF, A. (2004), Identidades asesinas. Madrid: Alianza.

MALGESINI, G. (1998), "Introducción”, en Malgesini, G. Cruzando fronteras. Migraciones en el sistema mundial. Madrid: Icaria-Fundación Hogar del Empleado.

MARTÍNEZ ALBERTOS, J.L. (2004) Curso general de redacción periodística. Barcelona: Mitre.

MENDOZA PÉREZ, C.L. (2004), "Circuitos y espacios transnacionales en la migración entre México y Estados Unidos, aportes de una encuesta de flujos". Migraciones Internacionales, vol. 2, $\mathrm{n}^{\circ}$ 3 , enero-junio.

MORENO, I. (2005a), "Globalización y cultura”, en Roche Cárcel, J. A. y Oliver Narbona, M. Cultura y Globalización. Entre el conflicto y el diálogo. Alicante: Universidad de Alicante.

MORENO, L. (2005b), "Integración y codesarrollo, ¿realidad o quimera?, en Abad, L. V. y otros Codesarrollo, migraciones y desarrollo mundial. Madrid: CYDEAL.

NAIR, S. y DE LUCAS, J. (1999), Inmigrantes. El desplazamiento en el mundo. Madrid: Ministerio de Trabajo y Asuntos Sociales. Secretaría General de Asuntos Sociales. Instituto de Migraciones y Servicios Sociales.

NAIR, S. (2006), Y vendrán las migraciones en tiempos hostiles. Barcelona: Bronce.

ORTEGA DOLZ, P. (2007), "La inmigración re-contada", en M. Lario Bastida, (coord.) (2007), Medios de Comunicación e Inmigración. Murcia: CAM, pp.257-271.

PARDO, N. G. (2007), "Niveles de organización del significado en el discurso", en Discurso y Sociedad, 1, pp. 85-115.

PINTOS, J. L. (2005), "Comunicación, construcción de la realidad e imaginarios sociales", en Utopía y praxis latinoamericana 10, 29, pp. 37-65.

PORTES, A. y BÔRÔTCZ, J. (1998), "Migración contemporánea. Perspectivas teóricas sobre sus determinantes y sus modalidades de incorporación", en Malgesini, G. Cruzando fronteras. Migraciones en el sistema mundial. Madrid: Icaria-Fundación Hogar del Empleado.

ROCHE CÁRCEL, J.A. y SERRA YOLDI, I. (2007), “Contradicciones culturales de las migraciones en la sociedad globalizada". Barcelona, PAPERS, 94.

RODRIGO ALSINA, M. (2007), "El periodismo ante el reto de la inmigración", en M. Lario Bastida, (coord.) (2007), Medios de Comunicación e Inmigración. Murcia: CAM, pp. 37-57.

SAFRANSKI, R. (2004), ¿Cuánta globalización podemos soportar? Barcelona: Tusquets.

SÁNCHEZ CAPDEQUÍ, C. (2004), Las máscaras del dinero. El simbolismo social de la riqueza. Barcelona: Anthropos.

SARTORI, G. (2003), La sociedad multiétnica. Pluralismo, multiculturalismo, extranjeros e islámicos. Madrid: Taurus.

SASSEN, S. (2007), Una sociología de la globalización. Buenos Aires: Katz.

SEN, A. (2007), Identidad y violencia. La ilusión del destino. Buenos Aires: Katz.

SENNET, R. (2006), La cultura del nuevo capitalismo. Barcelona: Anagrama.

SOLÉ, C. y CACHÓN, L. (2006), "Globalización e inmigración, los debates actuales", Madrid, REIS, 116, octubre-diciembre.

STEINGRESS, G. (2007), "El tiempo como fuente de valor e incertidumbre. Sobre la economía política del tiempo explotado en las sociedades avanzadas", en Roche Cárcel, J. A. Espacios y Tiempos Inciertos de la Cultura. Barcelona: Anthropos.

STIGLITZ, J. (2003), El malestar en la globalización. Madrid: Taurus.

UGUR, M. (1998), "Libertad de circulación versus exclusión, una reinterpretación de la división "propio"-“extraño" en la Unión Europea”, en Malgesini, G. Cruzando fronteras. Migraciones en el sistema mundial. Madrid: Icaria-Fundación Hogar del Empleado. 
VAN DIJK, T. A. (2003), Ideología y discurso. Una introducción multidisciplinaria. Barcelona: Ariel.

VAN DIJK, T. A. (2006), "Discurso y manipulación, discusión teórica y algunas aplicaciones", en Signos, 39, 60, pp.49-74.

VIRUELA MARTÍNEZ, R. (2007), "Migración y Nuevas Tecnologías de la Información y la Comunicación, inmigrantes rumanos en España", Madrid, Revista Migraciones, $\mathrm{n}^{\circ} 21$.

WALLERSTEIN, I. (2007), Geopolítica y geocultura. Ensayos sobre el moderno sistema mundial. Barcelona: Paidós.

\section{Breve currículo:}

\section{Juan Antonio Roche Cárcel}

Profesor Titular de Sociología en la Universidad de Alicante. Entre sus últimas publicaciones destacan, como autor, La sociedad evanescente, Anthropos, 2009; y como editor, Espacios y tiempos inciertos de la cultura, Anthropos 2007, y La sociología como una de las bellas artes. La influencia del arte y la literatura en el pensamiento sociológico, Anthropos, 2011. Es también autor de numerosos artículos en revistas especializadas nacionales y europeas y coordinador de los números monográficos de la Revista Política y sociedad, "Arte y poder", 46, 2007, y de Papers. Revista de sociología, Cultura y migraciones, 94, 2009. Ha sido coordinador de investigación del área de cultura y artes de la ESA (Asociación Europea de Sociología) y vicepresidente de la AESCA (Asociación Española de Sociología de la Cultura y de las Artes).

\section{Carmen Marimón Llorca}

Profesora Titular de Lengua española en la Universidad de Alicante. Ha publicado en revistas y editoriales especializadas trabajos sobre retórica y discurso y, en general, sobre diversos aspectos de la textualidad y del análisis gramatical y pragmático del español. Su último libro como autora es Análisis de textos en español. Teoría y práctica, de 2008. Es coeditora del volumen Intercultural Business Communication and Simulation and Gaming Methodology publicado en 2009 en Peter Lang y que recibió en 2010 el "First Researching Award Enrique Alcaraz" que concede AELFE (Asociación Europea de Lengua con Fines Específicos). Es miembro del Consejo de redacción de la revista ELUA, del Instituto Universitario de Lenguas Modernas Aplicadas (IULMA) y ha dirigido e impartido seminarios y cursos sobre aspectos aplicados de la lengua española. En la actualidad es Directora Académica del Centro Superior de Idiomas de la Universidad de Alicante. 